\title{
Physicochemical and sensory characteristics of pan bread samples available in the Brazilian market
}

\author{
Patricia Mello Garrido ISHIDA ${ }^{1}$, Caroline Joy STEEL ${ }^{1 *}$
}

\begin{abstract}
Pan bread samples available in the Brazilian market were evaluated for their physicochemical and sensory characteristics. Twelve pan breads, seven white and five whole grain breads, were evaluated. Moisture, water activity (Aw), firmness, and color $\left(L^{*}, a^{\star}, b^{\star}\right)$ of the crumb were evaluated on the first, fourth, seventh, and tenth days after purchasing the breads. Specific volume was evaluated on the first day of analysis with averages of 4.72 and $4.70 \mathrm{~mL} / \mathrm{g}$ for the white and whole grain breads, respectively. The average results on the first day of analysis were: $37.03 \%$ and $41.23 \%$ moisture, 0.954 and $0.966 \mathrm{Aw}, 276.27$ and 267.83 gf firmness, 74.73 and $64.45 \mathrm{~L}^{\star}$ values, 0.37 and $3.85 \mathrm{a}^{*}$ values, and 15.51 and $18.98 \mathrm{~b}^{\star}$ values for the white and whole grain breads, respectively. The samples showed an increase in firmness, reduction in moisture and Aw, and no color changes over time. A survey conducted prior to the acceptance test showed that the three most important factors influencing purchase were taste $(19.6 \%)$, tenderness $(16.8 \%)$, and expiration date of the product $(14.3 \%)$. The results showed that $37.2 \%$ of the panelists preferred white bread, $62.8 \%$ preferred bread with fibers, and $82.6 \%$ would probably or definitely buy white bread with fibers.
\end{abstract}

Keywords: dietary fiber; Internal Preference Mapping; sensory analysis; technological quality.

\section{Introduction}

Bread is a product rich in calories and widely consumed in Brazil; as a part of the Brazilian culture, it is eaten at breakfast and other meals. According to the Brazilian food standards legislation, bread is made from wheat flour or other flours, contains liquids, can be subjected or not to fermentation prior to cooking, and may contain other ingredients that do not change its characteristics. Bread can have different toppings, fillings, shapes, and textures (Brasil, 2005). Pan bread (also referred to as loaf bread or sliced bread) is the product in which the dough is baked in a loaf pan to give its characteristic format. White bread is not enriched with fibers, and whole grain bread is made from common wheat flour with wheat bran and/or whole grain flour and/or other ingredients with fibers that make the bread dark.

The Brazilian baked goods market has grown significantly in the last few years because of several factors such as the increase in purchasing power and options in the market, technological improvements, and appeal for healthy foods. Breads containing whole meal ingredients, fibers, and "light" claim (those with a reduced amount of some ingredient or energy value when compared to that of a conventional product) were the fastest growing products in the market due to consumers' demand for healthy foods. From 2009 to 2013 there was a 16.7\% increase in sales volume of processed breads in Brazil (Associação Brasileira das Indústrias de Massas Alimentícias, 2011, 2014).

Dietary fibers are beneficial for health maintenance and disease prevention. Regular fiber intake helps to prevent obesity, cardiovascular diseases, type 2 diabetes, metabolic syndrome, and constipation (Slavin, 2008; Mello \& Laaksonen, 2009; Holma et al., 2010).
The addition of fiber-rich ingredients to the dough causes changes in water absorption and quality of the bread (Sluimer, 2005). Rosell \& Santos (2010) studied the effect of $10 \%$ substitution of wheat flour by a mixture of fibers (inulin and white oat fiber, ratio not informed) and observed a decrease in specific volume and an increase in hardness. Hager et al. (2011) found that the moisture increased and the specific volume decreased with the use of $\beta$-glucan in bread. Sivam et al. (2011) found increased moisture and color changes in a bread sample containing pectin.

Despite the increased consumption of whole grain foods in Brazil, the daily fiber intake is still low. Madruga et al. (2009) investigated the frequency of consumption of dietary fiber in southern Brazil and concluded that $65.6 \%$ of the 3,993 individuals studied had low dietary fiber intake; this index is higher among men, adolescents, and people with low purchasing power. Mattos \& Martins (2000) studied the dietary fiber intake in the adult population in a city in Southeastern Brazil (Cotia, SP) and found daily intakes of $20 \mathrm{~g}$ of dietary fiber for women and $29 \mathrm{~g}$ for men. The authors concluded that, in general, dietary habits of those adults consisted of low fiber diets. In Brazil, the recommended daily intake is $25 \mathrm{~g}$ dietary fiber based on a 2,000-calorie diet (Brasil, 2003).

The consumption of fiber-enriched bread is an alternative approach to increase the intake of this component, but it is known that the appearance of whole grain bread may lead to rejection by some consumers who prefer a softer texture and white appearance, like that of conventional bread, which is made without the addition of ingredients to increase the fiber content. 
There is no study on Brazilian preference for white bread or whole grain bread. The present study aimed to evaluate the physicochemical and sensory characteristics of different white pan bread samples and whole grain bread samples available in the Brazilian market, identifying consumer preferences.

\section{Materials and methods}

\subsection{Pan bread}

Twelve samples of pan bread of different brands were purchased from the local market (Campinas, SP), as follows: 7 white bread samples, of which five were chosen for being the best-selling brands in the Brazilian market (WHI1, WHI4, WHI5, WHI6, and WHI7), one with inulin (WHI2), and one from an artisan bakery (WHI3); and 5 whole grain bread samples, of which one with wheat bran (WHO1), one from an artisan bakery (WHO2), one with polydextrose (WHO3), one with visible grains (WHO5), and one "light" bread (reduced carbohydrates; with no sugar) with visible grains (WHO4). Since the products had no manufacture date printed on the labels (not required by law), the collection was performed according to similar expiration dates, which varied from 5 to 11 days from the purchase date. Although the expiration date (10 days) was reached prior to final analysis of most samples, none of them showed visible growth of molds; therefore, the results were considered reliable. The bread samples were kept in their original packages in a room at $20 \pm 2{ }^{\circ} \mathrm{C}$ during the period of analysis. This storage temperature was chosen because tests with other pan bread samples stored at room temperature in Campinas, SP (average temperature of $35^{\circ} \mathrm{C}$ ), showed growth of yeasts and molds within 10 days of storage. The list of ingredients, the dietary fiber content, and other information displayed on the labels are shown in Table 1.

\subsection{Physicochemical properties of pan bread samples}

The samples were evaluated for: (a) specific volume by the millet seed displacement method, described by AACC Method 10-05.01 (American Association of Cereal Chemists, 2010). Since the pan bread samples were sliced, they were packaged in a PVC film in order to facilitate measuring the volume of the whole loaf, and the determination was performed in triplicate; (b) crumb moisture, determined by AACC Method 44-15.02 (American Association of Cereal Chemists, 2010), in three replicates. Bread crumb was considered as the entire internal portion of the bread, $1 \mathrm{~cm}$ from the edges; (c) water activity (Aw) of the crumb, measured using an AquaLab Series 3TEV instrument (Decagon Devices, Inc., Pullman, WA, USA) at $25^{\circ} \mathrm{C}$ in three replicates; (d) crumb texture, determined by AACC Method 74-10.02 (American Association of Cereal Chemists, 2010). This analysis was performed using a texture analyzer (TA-XT2, 25 kg load, Stable Micro Systems, Godalming, Surrey, England) in six replicates; and (e) crumb color, performed in four replicates by exposing two superimposed slices arranged horizontally to the incidence of light on a spectrophotometer (HunterLab ColorQuest II, Hunter Associates Laboratory, Inc., Reston, Virginia, USA), D65 illuminant, $10^{\circ}$ observer angle, reflectance RSIN, using the CIELab system. Moisture, Aw, texture, and color measurements were carried out on days 1,4 , 7 , and 10 after purchase of samples.

\subsection{Sensory evaluation of pan bread samples}

For the sensory analysis, six samples (3 white bread and 3 whole grain bread samples) were chosen as follows: white bread samples WHI3, WHI4, and WHI5, and whole grain bread samples WHO1, WHO2, and WHO4. The samples WHI3 and WHO2 referred to white bread and whole grain bread produced in an artisan bakery; WHI4 and WHI5 showed the lowest firmness during the period of time evaluated. Sample WHO1 had the lowest specific volume and had only wheat bran as fiber source (displayed as wheat fiber), and WHO4 referred to a "light" bread sample and had visible grains. The samples had similar expiration dates that were sufficient for the analysis period of 10 days (except for the samples from the artisan bakery, which had an expiration date of five days and were purchased on the same day of manufacture). The bread samples were kept in their original packages in a room at $20 \pm 2{ }^{\circ} \mathrm{C}$. Sensory analysis was performed on the fourth day after purchase.

One hundred and twenty one panelists of both sexes aged 18-50 years were recruited for the test. A survey of frequency of consumption and preferences was performed prior to the analysis. An acceptance test was also applied to evaluate the sensory attributes appearance, aroma, taste, texture, and overall impression using a 9-point unstructured hedonic scale (from "disliked very much" to "liked very much"). Purchase intention was assessed using a 5-point scale anchored by the terms "certainly would not buy" to "certainly would buy" (Meilgaard \& Civille, 1999). The present study was approved by the Research Ethics Committee of the School of Medical Sciences - UNICAMP (Approval \# CEP 1243/2010).

\subsection{Statistical analysis}

The results were submitted to analysis of variance (ANOVA). The Tukey test $(\mathrm{p}<0.05)$ was used for comparison of means using the software SAS ${ }^{\bullet} 9.2$ (SAS Institute, 2009). For the attribute overall impression, Principal Component Analysis (PCA) was applied using the XLSTAT software (2007.8.03 version, Addinsoft, 2007).

\section{Results and discussion}

\subsection{Ingredients listed on the labels}

The fiber sources were whole wheat flour, wheat bran, inulin, polydextrose, oat, soy, rye, corn, linseed, and barley flours. From this list, only inulin, polydextrose, and oat flour (containing $\beta$-glucans) are considered sources of soluble fiber. The others are sources of insoluble fiber but may contain a fraction of soluble fiber.

The dietary fiber content of most white bread samples varied from 0.9 to $1.5 \mathrm{~g} / 50 \mathrm{~g}$, and only one sample showed high fiber content, $5.1 \mathrm{~g} / 50 \mathrm{~g}$ (inulin). The whole grain bread samples had content from 3.2 to $5.7 \mathrm{~g} / 50 \mathrm{~g}$, two samples showed high fiber content $(\geq 5 \mathrm{~g} / 50 \mathrm{~g})$, and again only one sample (from the artisan bakery) had values below this range, $1.3 \mathrm{~g} / 50 \mathrm{~g}(<2.5 \mathrm{~g} / 50 \mathrm{~g})$, 
Table 1. Identification, list of ingredients, fiber content, expiration date, and price of pan bread samples from the Brazilian market.

\begin{tabular}{|c|c|c|c|c|}
\hline Sample & Ingredients displayed on the labels & $\begin{array}{c}\text { Fiber } \\
\text { content }^{1 / 5} 50 \mathrm{~g}\end{array}$ & $\begin{array}{c}\text { Expiration } \\
\text { Date }^{2} \text { (days) }\end{array}$ & $\begin{array}{c}\text { Price }^{3} \\
(\mathrm{R} \$ / \mathrm{kg}) \\
\end{array}$ \\
\hline WHI3 & $\begin{array}{l}\text { Wheat flour enriched with iron and folic acid, vegetable fat, sugar, milk powder, salt, } \\
\text { yeast and flour improver [corn starch and/or cassava starch and/or wheat flour and sugar, } \\
\text { stabilizers (polyoxyethylene sorbitan monooleate and soy lecithin), flour improvers (ascorbic } \\
\text { acid and alpha-amylase), artificial flavoring, and coloring (synthetic beta-carotene)]. }\end{array}$ & $1.1 \mathrm{~g}$ & 5 & 5.87 \\
\hline WHI4 & $\begin{array}{l}\text { Wheat flour enriched with iron and folic acid, sugar, vegetable fat, salt, monocalcium } \\
\text { phosphate and tricalcium phosphate, vitamins PP, B6, B1, and B12, emulsifiers (sodium } \\
\text { stearoyl-2-lactyl-lactate, polysorbate } 80 \text {, and fatty acid monoglycerides), and preservative } \\
\text { (calcium propionate). }\end{array}$ & $1.3 \mathrm{~g}$ & 7 & 6.40 \\
\hline WHI7 & $\begin{array}{l}\text { Wheat flour enriched with iron and folic acid, water, yeast, sugar, vegetable fat (palm oil), } \\
\text { refined salt, soy flour, wheat gluten, emulsifiers (mono and diglycerides of fatty acids, } \\
\text { sodium stearoyl-2-lactyl-lactate and soy lecithin), preservatives (calcium propionate } \\
\text { and sorbic acid), "butter" natural identical flavoring, acidulant (lactic acid) and flour } \\
\text { improvers (alpha amylase and ascorbic acid). }\end{array}$ & $0.9 \mathrm{~g}$ & 11 & 6.25 \\
\hline WHO1 & $\begin{array}{l}\text { Wheat flour enriched with iron and folic acid, fiber, wheat, sugar, hydrogenated vegetable } \\
\text { fat, salt, gluten, yeast, and preservative (calcium propionate). }\end{array}$ & $3.2 \mathrm{~g}$ & 9 & 10.01 \\
\hline WHO2 & $\begin{array}{l}\text { Wheat flour enriched with iron and folic acid, vegetable fat, sugar, milk powder, salt, } \\
\text { yeast and flour improver [corn starch and/or cassava starch and/or wheat flour and sugar, } \\
\text { stabilizers (polyoxyethylene sorbitan monooleate and soy lecithin), flour improvers } \\
\text { (ascorbic acid and alpha-amylase), artificial flavoring and coloring (synthetic beta- } \\
\text { carotene)], and preservative (calcium propionate). }\end{array}$ & $1.3 \mathrm{~g}$ & 5 & 8.97 \\
\hline WHO4 & $\begin{array}{l}\text { Wheat flour enriched with iron and folic acid, wheat bran, gluten, dietary fiber, oat bran, } \\
\text { rye flakes, sunflower seeds, salt, barley flour, corn flour fortified with iron and folic acid, } \\
\text { sesame, preservative (calcium propionate), emulsifiers (calcium stearoyl-2-lactyl-lactate, } \\
\text { polysorbate } 80 \text {, and guar gum), and sweetener (acesulfame K). }\end{array}$ & $5.2 \mathrm{~g}$ & 10 & 9.91 \\
\hline WHO5 & $\begin{array}{l}\text { Wheat flour enriched with iron and folic acid, gluten, sugar, wheat bran, sunflower seeds, } \\
\text { flaxseed, oat flakes, rye flour, soy flakes, triticale grain, salt, flaxseed flour, wheat germ, } \\
\text { canola oil, calcium carbonate, malt extract, malt flour, vitamins A, D, and E, soy flour, } \\
\text { preservative (calcium propionate), acidulant (lactic acid), and sweetener sucralose. }\end{array}$ & $5.7 \mathrm{~g}$ & 10 & 8.94 \\
\hline
\end{tabular}

WHI1 to WHI7: white breads; WHO1 to WHO5: whole grain breads; 1-Fiber content printed on the label; 2-Number of days remaining before expiration from the date of purchase; 3 -Values referring to June/2010.

and thus it is not considered source of fiber under the Brazilian legislation (Brasil, 2012).

With respect to the price of the pan bread samples acquired in June 2010, the white breads showed an average cost of R\$ $7.31 / \mathrm{kg}$ (USD 3.18/kg), and the price of the whole grain breads was R\$ 9.55/kg (USD 4.16/kg) (units of $350 \mathrm{~g}$ to $500 \mathrm{~g}$ ); therefore, the whole grain bread samples were, in average, $30.64 \%$ more expensive than the white bread samples.

\subsection{Physicochemical analyses}

The samples showed specific volume values varying from 3.88 to $5.37 \mathrm{~mL} / \mathrm{g}$. There was no statistical difference $(\mathrm{p}<0.05)$ between the white bread and whole grain bread samples, which had an average specific volume of $4.72 \mathrm{~mL} / \mathrm{g}$, and $4.70 \mathrm{~mL} / \mathrm{g}$, respectively. Sample WHO4 had the highest specific volume $(5.37 \mathrm{~mL} / \mathrm{g})$, which is a "light" product (with reduced carbohydrate content), enriched with different sources of fiber 
(wheat bran, oat bran, rye flakes, barley flour, and corn meal). It has a blend of emulsifiers (calcium stearoyl-2-lactyl-lactate, polysorbate 80 , and guar gum), which may have contributed to the increased volume, besides the $\alpha$-amylase and other enzymes that may be present although they are not listed as ingredients. Emulsifiers improve dough handling, increase loaf volume, improve the texture of the crumb, and improve shelf life (Moayedallaie et al., 2010; Gandra et al., 2008). The class and type of flour and the type and amount of fiber added may also affect the specific volume (Sluimer, 2005). The mean specific volume found in this study is consistent with those reported by Esteller \& Lannes (2005), who found a mean value of $4.10 \mathrm{~mL} / \mathrm{g}$ for Brazilian pan bread without fibers. Soares Júnior et al. (2009) found similar value for white bread $(4.43 \mathrm{~mL} / \mathrm{g})$, and in a study on partial substitution of wheat flour by toasted rice bran, the authors found a decrease in specific volume, which was $3.68 \mathrm{~mL} / \mathrm{g}$ and $2.70 \mathrm{~mL} / \mathrm{g}$ for $7.5 \%$ and $30 \%$ substitutions respectively.

The addition of bran or fiber generally weakens the structure of the bread by reducing the volume and elasticity of the crumb (Salmenkallio-Marttila et al., 2001). This effect is attributed to the interaction between the fiber and gluten, which leads to a decrease in gas retention capacity (Gómez et al., 2003).

The moisture of whole grain bread samples on the first day was higher than that of the white bread samples and kept higher on the other days, except for sample WHO2, which was produced in an artisan bakery. This product also had a low content of dietary fiber per serving ( $1.3 \mathrm{~g} / 50 \mathrm{~g}$ bread), indicating a low substitution level of wheat flour by fiber. Sample WHI2 had the lowest moisture content on all days of analysis, possibly due to the high inulin content. Inulin is a soluble fiber that decreases the water absorption of the dough (Hager et al., 2011; Peressini \& Sensidoni, 2009; Wang et al., 2002). Peressini \& Sensidoni (2009) observed a decrease in moisture content of bread samples containing inulin compared to that of the control sample without fibers, and this decrease was larger with increased inulin content.

The average moisture content of the white bread samples was $37.07 \%$ on the first day and $34.14 \%$ on the tenth day, while the whole grain bread samples had values of $41.23 \%$ and $37.22 \%$ in the same period of analysis, respectively. During shelf life, the moisture content decreased for all samples $(\mathrm{p}<0.05)$ (Figure 1(a)) due to various factors, including migration of water from crumb towards crust, water loss to the atmosphere caused by the permeability of the packaging, and starch retrogradation (Cauvain, 1998). Although Esteller \& Lannes (2005) found $29.99 \%$ moisture for commercial pan bread, the comparison of this result with that of the present study is impaired by the differences in terms of time of purchase and manufacturing methods of commercial products.

With respect to the whole grain bread samples, moisture values were slightly higher than those obtained by Gandra et al. (2008), who studied bread containing wheat bran (20\% flour basis) and found moisture contents of $34.13 \%$ and $31.55 \%$ on the first and seventh day of analysis, respectively.

The whole grain bread samples had higher moisture than the white bread samples. Soares Júnior et al. (2009) also observed an $8 \%$ increase in moisture content of breads with $7.5 \%$ substitution of wheat flour by roasted rice bran. This occurred because fibers absorb more water during the mixing stage and have high water retention capacity (Katina, 2003).

The mean water activity values (Aw) on the first and tenth day were 0.954 and 0.943 , for the white bread samples, and 0.965 and 0.956 , for the whole grain bread samples, respectively. Sample WHI2 showed the lowest Aw in the whole period of analysis. This product is high in both dietary fiber $(5.1 \mathrm{~g} / 50 \mathrm{~g})$ and inulin (4.0 g/50 g), as displayed on the label. Inulin reduces the water absorption of the dough and causes a decrease in free water. During shelf life, the samples showed reduced Aw caused by water loss (Figure 1(a)).

The mean firmness values of the white bread samples and whole grain bread samples were 267.83 gf and 276.27 gf, on the first day, and 512.15 gf and 496.87 gf, on the tenth day, respectively (Figure 1(b)). Sample WHI2, with inulin, showed the highest firmness, and WHI4, with low carbohydrate content, had the lowest firmness on all days of analysis. Inulin caused lower moisture and Aw for sample WHI2, reflecting directly on the texture of the bread by increasing firmness. Peressini \& Sensidoni (2009) and Wang et al. (2002) also observed an increase in firmness by adding inulin. Sample WHI4 may contain enzymes such as maltogenic $\alpha$-amylase, glucoamylase or others not displayed on the label, which may have led to low firmness during storage. Among the whole grain bread samples, sample WHO2 had low firmness on the first days (152.3 gf and 285.7 gf on the first day and on the fourth day, respectively), but it had statistically $(\mathrm{p}<0.05)$ significant higher firmness than the other whole grain bread samples after the seventh day (569.4 gf). This may be due to the fact that this sample was produced in an artisan bakery without the use of specific additives (emulsifiers and enzymes) that preserve the characteristics of the crumb during storage, besides having low fiber content. The bread making method used, either straight-dough or sponge-anddough or other variations, may also have affected the firmness of sample WHO2. The straight-dough method consists of only one stage, in which the ingredients are mixed all together in one step before fermentation. In contrast, the sponge-anddough method consists of two distinct stages, in which part of the water is added to part of the flour, yeast, and sometimes sugar and other ingredients, and this mixture is fermented (and called "sponge") prior to the addition of the remaining water, flour and other ingredients to form dough. This method is used to dissolve the gluten (in very strong flour), to activate the yeast, to develop flavor, and to facilitate the formation of the dough (Sluimer, 2005). During storage, all samples showed an increase in firmness due to the retrogradation of starch (Zobel $\&$ Kulp, 1996). Starch retrogradation occurs during the cooling period after baking, in which the amylose and amylopectin chains aggregate forming crystalline double helices stabilized by hydrogen bonds, leading to bread hardening (Chinachoti \& Vodovotz, 2001; Zobel \& Kulp, 1996). Gómez et al. (2003) also found an increase in firmness for both the control sample (without fibers) and those containing $2 \%$ and $5 \%$ fiber (cellulose, pear, cocoa, coffee, and wheat) after 24, 48, and $72 \mathrm{~h}$. Alaunyte et al. (2012), Purhagen et al. (2012), and Sullivan et al. (2010) also found this phenomenon in bread samples containing different types of fibers. 

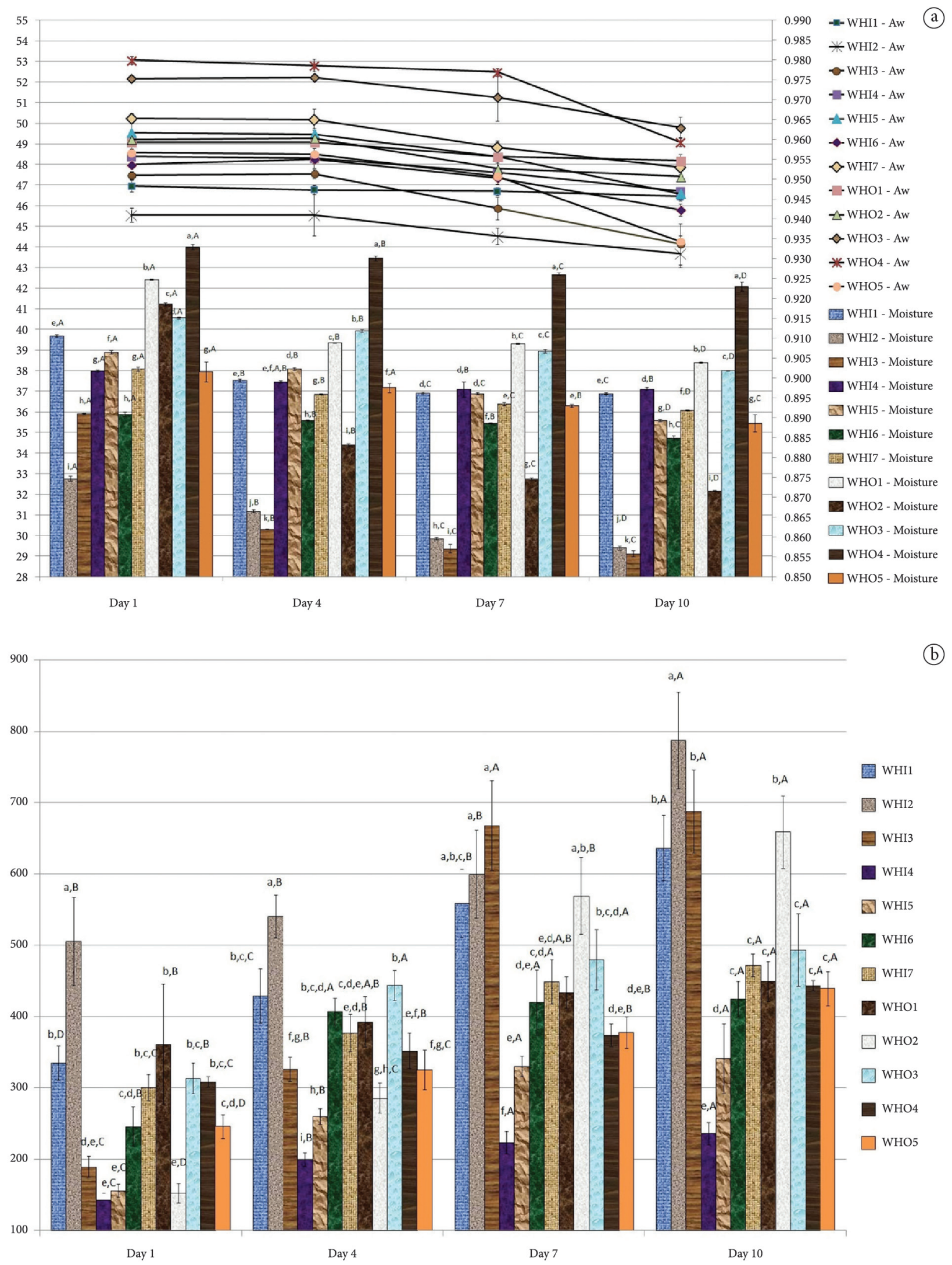

Figure 1. Moisture (\%), water activity (Aw) and firmness (gf) of pan bread samples on days 1, 4, 7, and 10 after purchase; (a) Moisture and water activity and (b) firmness; the bars represent means \pm standard deviations ( $\mathrm{n}=3$ for moisture; $\mathrm{n}=6$ for firmness); lowercase letters refer to the comparison between samples on the same day of storage, and capital letters refer to the comparison between the days of analysis for the same sample; means followed by different letters differ by the Tukey test ( $<$ <0.05); WHI1-WHI7: white breads; WHO1-WHO5: whole grain breads. 
As for the color parameters, on the first day of analysis, the $\mathrm{L}^{*}$ values (lightness) of the white bread samples and whole grain bread samples were 74.73 and 64.45 , respectively. This is expected because the whiter the sample, the higher the $L^{*}$ value. The mean $\mathrm{a}^{*}$ values (-green, + red) were 0.37 and 3.85 for white breads and whole grain breads, respectively, showing that the whole grain bread samples were more reddish-colored than the white bread samples. The $b^{*}$ values (-blue, +yellow) values were 15.51 and 18.98 , respectively, indicating that the whole grain bread samples were also more yellowish-colored than the white bread samples (Figure 2). Esteller \& Lannes (2005) obtained L*, $\mathrm{a}^{*}$, and $\mathrm{b}^{*}$ values of $62.37,1.14$, and 10.88 for the crumb of white breads, respectively. No changes were observed in the color of the samples over time.

\subsection{Sensory analysis}

Of the 121 consumers, $32.2 \%$ were male and $67.8 \%$ female, $88.4 \%$ aged between 18 and 30 years, and $11.6 \%$ from 31 to 50 years. In addition, $72.7 \%$ of the panelists eat pan bread 2-7 times a week, and $9.9 \%$ rarely consume this product. According to the consumers, the three most important factors influencing the purchase of pan bread were taste (19.6\%), tenderness $(16.8 \%)$, and expiration date (14.3\%). Appearance, price, health benefits, and fiber content were secondary factors. The last factor considered among the 10 items studied was sugar content $(0.8 \%)$. When data were analyzed based on gender, men chose taste, tenderness, and price. Although women were detail-oriented and considered storage time and men preferred to consider price, both groups indicated the parameters taste and tenderness as important factors when buying pan bread. Pohjanheimo et al. (2010) studied the behavior pattern of Finnish adolescents (13-15 years) towards choice of bread and health, and found that most adolescents mentioned flavor and soft texture as the most important factors influencing purchase of bread.

When consumers were asked whether they preferred to eat white bread or bread with fibers, $37.2 \%$ preferred white bread, and the majority preferred bread with fibers (62.8\%); when asked about buying white bread with fibers, $82.6 \%$ would probably or definitely buy the product, and this percentage reached $87.2 \%$ among men. Pohjanheimo et al. (2010) found that rye bread with fiber, which is widely consumed in Finland, was preferred over white bread without fiber by most adolescents. According to these consumers, the positive behavior of the family towards the consumption of fiber from childhood increased fiber intake in adulthood.

Figure 3(a) shows the mean scores assigned to each sample regarding the attributes evaluated in the affective sensory test. For the attribute appearance, the samples received similar scores, except for sample $\mathrm{WHO} 2$, which is an artisan bakery product and received a lower score $(\mathrm{p}<0.05)$. The samples differed slightly regarding aroma. Sample WHO4 showed less acceptable taste than the other samples since it was a "light" product containing sweeteners and had a bitter aftertaste, as reported by several consumers. Regarding the attribute texture, the white bread samples were more accepted than the whole grain bread samples since only sample WHO1 received similar scores to those of the white breads. These factors influenced the overall impression of both samples, WHO2 and WHO4, which also had lower overall impression scores $(\mathrm{p}<0.05)$. Battochio et al. (2006) studied the acceptance of three Brazilian whole grain bread samples and found similar averages for these attributes, 6.14, 6.40, 5.35, 6.09 , and 6.31 for appearance, aroma, taste, texture, and overall impression, respectively.
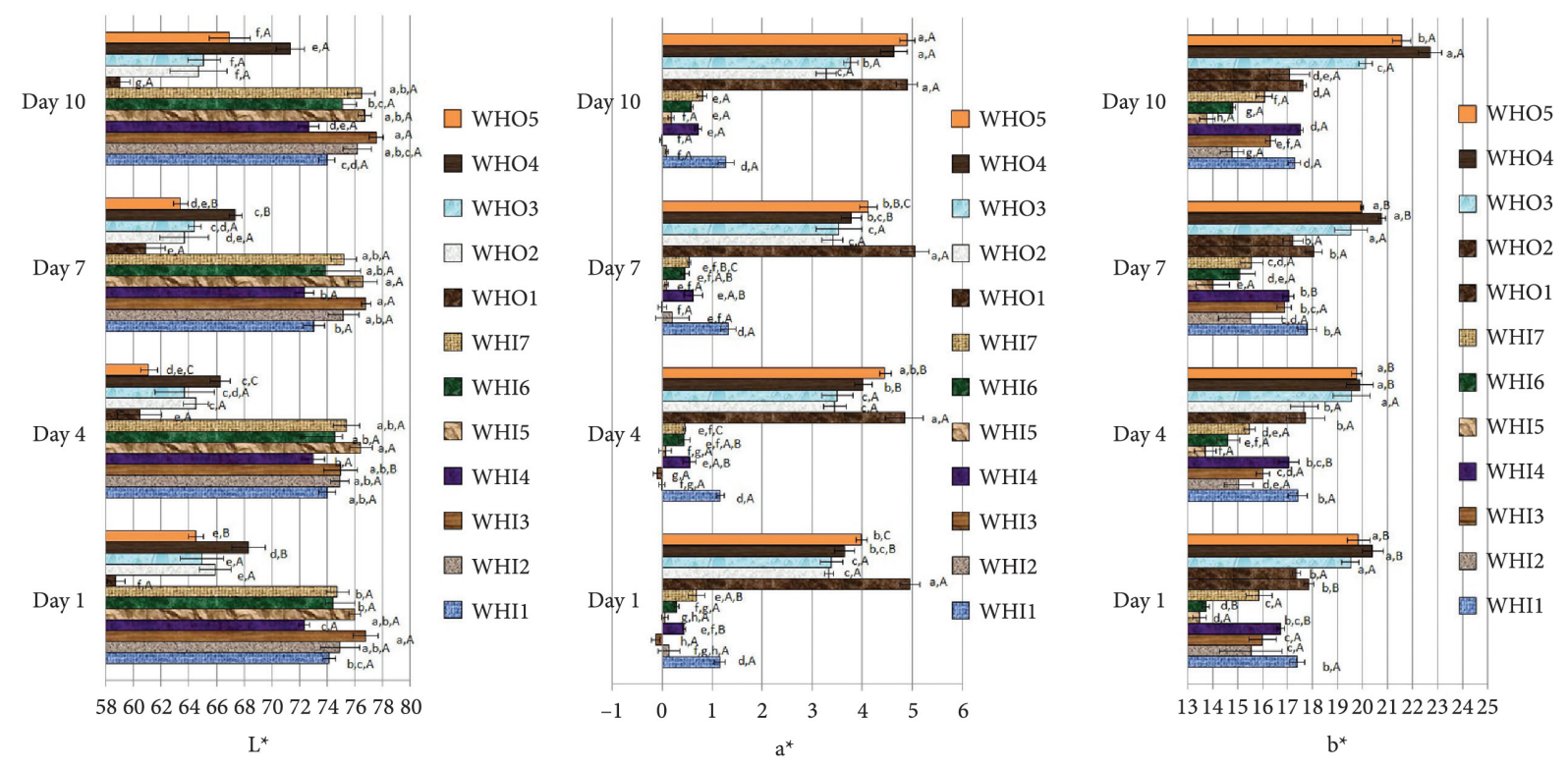

Figure 2. Color parameters $\mathrm{L}^{*}, \mathrm{a}^{*}$ and $\mathrm{b}^{*}$ of pan breads on days $1,4,7$, and 10 after purchase; the bars represent means \pm standard deviations $(\mathrm{n}=4)$; lowercase letters refer to the comparison between samples on the same day of storage, and capital letters refer to comparisons between the days of analysis for the same sample; means followed by different letters differ by the Tukey test ( $\mathrm{p}<0.05)$, WHI1-WHI7: white breads; WHO1-WHO5: whole grain breads. 

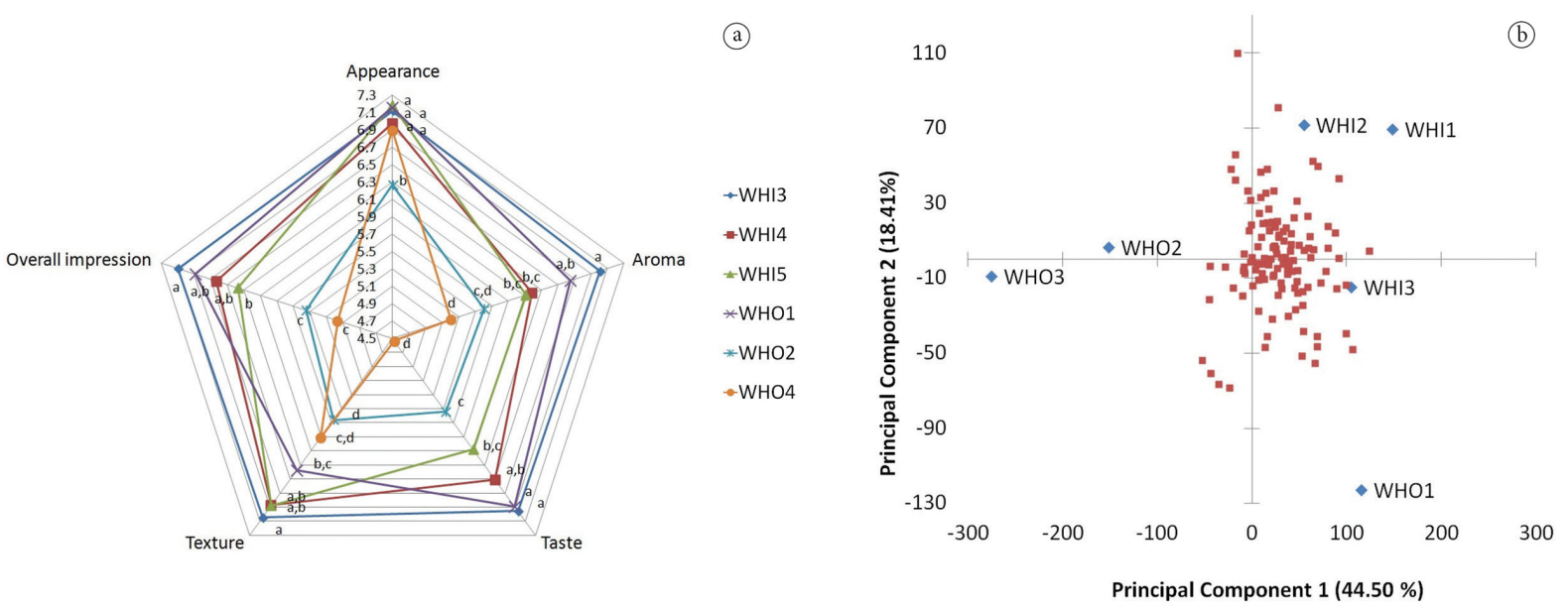

Figure 3. Average acceptance and Internal Preference Mapping (IPM) of commercial pan bread samples for global impression test scores ( $\mathrm{n}=121$ ) obtained for white bread samples (WHI3, WHI4, and WHI5) and whole grain bread samples (WHO1, WHO2 and WHO4); (a) Acceptance using a $9-\mathrm{cm}$ unstructured hedonic scale. Means followed by different letters for the same parameter differ by the Tukey test (p <0.05); (b) IPM: The squares refer to the 121 panelists.

The Internal Preference Mapping was obtained with the values of overall impression of the commercialized pan bread samples, assessed by Principal Component Analysis (PCA). The two main components explained $62.91 \%$ of the variation between the samples in relation to the overall impression (Figure 3(b)). Although all samples showed a good degree of acceptance, it was observed that sample WHI5 was very well accepted because it exhibited the characteristics desired by the consumers. In contrast, sample WHO4 was less accepted because of its bitter aftertaste and whole grain composition. It can also be observed that sample WHO1 is different from both $\mathrm{WHO} 2$ and $\mathrm{WHO} 4$ since they are located in different quadrants; WHI5 is different from WHI3 and WHI4 for the same reason. Samples WHO2 and WHO4 are located close to each other and are thus similar in terms of acceptance, which also occurred to samples WHI3 and WHI4. Although samples WHI5 and WHO1 had similar acceptance since they are located in the same quadrant, WHI5 is located closer to a larger number of consumers, and therefore it can be said that it was better accepted than WHO1.

With respect to purchase intention, the pan bread samples were well accepted since $82.6 \%$ consumers would probably or definitely buy sample WHI3, followed by $74.4 \%$ for sample WHO1 and $70.2 \%$ for WHI4. The bread samples with lower scores were WHO2 (45.5\%) and WHO4 (27.3\%). The latter received the lowest scores, probably due to its residual bitter taste, as reported by the consumers. This result corroborates those of the Internal Preference Mapping, which showed that sample WHO4 was the least accepted.

\section{Conclusions}

The white pan bread samples had low dietary fiber contents, while the whole grain bread samples showed high concentrations of this component, according to the Brazilian food standards legislation. Only one white bread with fiber, which was classified as white due to the color of the crumb, showed high fiber content (5.1 g inulin/50 g sample). In contrast, the whole grain bread from an artisan bakery had low dietary fiber $(1.3 \mathrm{~g} / 50 \mathrm{~g})$ and was not considered a fiber source.

Consumers scored taste, tenderness, and expiration date as the three most important factors when purchasing pan bread. Taste and tenderness were the most important factors chosen by both men and women. Therefore, these factors should be taken into account to increase the acceptance of products containing fibers.

In general, when compared to white breads, the whole grain breads available in the Brazilian market had higher values of moisture content, $A w, a^{*}$, and $b^{*}$, and had lower $L^{*}$ values and sensory acceptance, according to the Internal Preference Mapping. The white bread samples and whole grain bread samples were not significantly different $(p<0.05)$ in terms of both specific volume and instrumental firmness. It is important to remember that formulation, manufacturing processes, and manufacturing dates of commercial breads were different, which may lead to differences in bread quality.

The production of white pan bread with fibers seems to be an alternative to increase fiber intake since most consumers $(82.6 \%)$ say they probably or definitely would buy this product when available in the market.

\section{Acknowledgements}

The authors gratefully acknowledge the National Council for Scientific and Technological Development (CNPq) for granting a scholarship to the author Patricia Mello Garrido Ishida. 


\section{References}

Addinsoft. (2007). XLSTAT 2007.8.03 for Excel. Paris.

Alaunyte, I., Stojceska, V., Plunkett, A., Ainsworth, P., \& Derbyshire, E. (2012). Improving the quality of nutrient-rich Teff (Eragrostis tef) breads by combination of enzymes in straight dough and sourdough breadmaking. Journal of Cereal Science, 55(1), 22-30. http://dx.doi. org/10.1016/j.jcs.2011.09.005.

American Association of Cereal Chemists - AACC. (2010). International approved methods. 11th ed. St. Paul: AACC International.

Associação Brasileira das Indústrias de Massas Alimentícias - ABIMA (2011). Cresce o setor de pães industrializados. São Paulo. Retrieved from http://www.abima.com.br

Associação Brasileira das Indústrias de Massas Alimentícias - ABIMA (2014). Estatística do mercado nacional: pães industrializados. São Paulo. Retrieved from http://www.abima.com.br

Battochio, J. R., Cardoso, J. M. P., Kikuchi, M., Macchione, M., Modolo, J. S., Paixão, A. L., Pinchelli, A. M., Silva, A. R., Sousa, V. C., Wada, J. K. A., Wada, J. K. A., \& Bolini, H. M. A. (2006). Perfil sensorial de pão de forma integral. Ciência e Tecnologia de Alimentos, 26(2), 428-432. http://dx.doi.org/10.1590/S0101-20612006000200028.

Brasil, Agência Nacional de Vigilância Sanitária - ANVISA. (2003). Regulamento técnico sobre rotulagem nutricional de alimentos embalados (Resolução RDC no 360, de 23 de dezembro de 2003). Diário Oficial da União. Retrieved from http://www.anvisa.gov.br

Brasil, Agência Nacional de Vigilância Sanitária - ANVISA. (2005). Regulamento técnico para produtos de cereais, amidos, farinhas e farelos (Resolução RDC no 263, de 22 de setembro de 2005). Diário Oficial da União. Retrieved from http://www.anvisa.gov.br

Brasil, Agência Nacional de Vigilância Sanitária - ANVISA. (2012). Regulamento técnico sobre informação nutricional complementar (Resolução RDC no 54, de 12 de novembro de 2012). Diário Oficial da União. Retrieved from http://www.anvisa.gov.br

Cauvain, S. P. (1998). Improving the control of staling in frozen bakery products. Trends in Food Science \& Technology, 9(2), 56-61. http:// dx.doi.org/10.1016/S0924-2244(98)00003-X.

Chinachoti, P., \& Vodovotz, Y. (2001). Bread staling. New York: CRC Press LLC. 177 p.

Esteller, M. S., \& Lannes, S. C. S. (2005). Parâmetros complementares para fixação de identidade e qualidade de produtos panificados. Ciência e Tecnologia de Alimentos, 25(4), 802-806. http://dx.doi. org/10.1590/S0101-20612005000400028.

Gandra, K. M., Del Bianchi, M., Godoy, V. P., Queiroz, F. P. C., \& Steel, C. J. (2008). Aplicação de lipase e monoglicerídeo em pão de forma enriquecido com fibras. Ciência e Tecnologia de Alimentos, 28(1), 182-192. http://dx.doi.org/10.1590/S0101-20612008000100027.

Gómez, M., Ronda, F., Blanco, C. A., Caballero, P. A., \& Apesteguía, A. (2003). Effect of dietary fibre on dough rheology and bread quality. European Food Research and Technology, 216, 51-56.

Hager, A. S., Ryan, L. A. M., Schwab, C., G囚nzle, M. G., O’Doherty, J. V., \& Arendt, E. K. (2011). Influence of the soluble fibres inulin and oat $\beta$-glucan on quality of dough and bread. European Food Research and Technology, 232(3), 405-413. http://dx.doi.org/10.1007/s00217010-1409-1.

Holma, R., Hongisto, S.-M., Saxelin, M., \& Korpela, R. (2010). Constipation is relieved more by rye bread than wheat bread or laxatives without increased adverse gastrointestinal effects. The Journal of Nutrition, 140(3), 534-541. http://dx.doi.org/10.3945/ jn.109.118570. PMid:20089780
Katina, K. (2003). High-fibre baking. In S. P. Cauvain (Ed.), Bread making: improving quality (cap. 23, pp. 487-499). England: Woodhead Publishing Limited.. http://dx.doi.org/10.1533/97818 55737129.2.487.

Madruga, S. W., Araújo, C. L., \& Bertoldi, A. D. (2009). Frequency of fiber-rich food intake and associated factors in a Southern Brazilian population. Cadernos de Saude Publica, 25(10), 2249-2259. http:// dx.doi.org/10.1590/S0102-311X2009001000015. PMid:19851624

Mattos, L. L., \& Martins, I. S. (2000). Consumo de fibras alimentares em população adulta. Revista de Saude Publica, 34(1), 50-55. http:// dx.doi.org/10.1590/S0034-89102000000100010. PMid:10769361

Meilgaard, M., \& Civille, G. V. (1999). Sensory evaluation techniques. 3rd ed. New York: CRC Press. http://dx.doi.org/10.1201/9781439832271.

Mello, V. D., \& Laaksonen, D. E. (2009). Fibras na dieta: tendências atuais e benefícios à saúde na síndrome metabólica e no diabetes melito tipo 2. Arquivos Brasileiros de Endocrinologia e Metabologia, 53(5), 509-518. http://dx.doi.org/10.1590/S000427302009000500004. PMid:19768242

Moayedallaie, S., Mirzaei, M., \& Paterson, J. (2010). Bread improvers: comparison of a range of lipases with a traditional emulsifier. Food Chemistry, 122(3), 495-499. http://dx.doi.org/10.1016/j. foodchem.2009.10.033.

Peressini, D., \& Sensidoni, A. (2009). Effect of soluble dietary fiber addition on rheological and breadmaking properties of wheat doughs. Journal of Cereal Science, 49(2), 190-201. http://dx.doi. org/10.1016/j.jcs.2008.09.007.

Pohjanheimo, T., Luomala, H., \& Tahvonen, R. (2010). Finnish adolescents' attitudes towards wholegrain bread and healthiness. Journal of the Science of Food and Agriculture, 90(9), 1538-1544. http://dx.doi.org/10.1002/jsfa.3982. PMid:20549809

Purhagen, J. K., Sjöö, M. E., \& Eliasson, A. C. (2012). Fibre-rich additives - the effect on staling and their function in freestanding and pan-baked bread. Journal of the Science of Food and Agriculture, 92(6), 1201-1213. http://dx.doi.org/10.1002/jsfa.4684. PMid:22052714

Rosell, C. M., \& Santos, E. (2010). Impact of fibers on physical characteristics of fresh and staled bake off bread. Journal of Food Engineering, 98(2), 273-281. http://dx.doi.org/10.1016/j. jfoodeng.2010.01.008.

Salmenkallio-Marttila, M., Katina, K., \& Autio, K. (2001). Effect of bran fermentation on quality and microstructure of high-fibre wheat bread. Cereal Chem., 78(4), 429-435. http://dx.doi.org/10.1094/ CCHEM.2001.78.4.429.

SAS Institute. (2009). Base $S A S^{\varpi}$ 9.2: procedures guide. 2nd ed. Cary. $1704 \mathrm{p}$

Sivam, A. S., Sun-Waterhouse, D., Waterhouse, G. I. N., Quek, S., \& Perera, C. O. (2011). Physicochemical properties of bread dough and finished bread with added pectin fiber and phenolic antioxidants. Journal of Food Science, 76(3), H97-H107. http://dx.doi.org/10.1111/ j.1750-3841.2011.02086.x. PMid:21535837

Slavin, J. L. (2008). Position of the American Dietetic Association: health implications of dietary fiber. Journal of the American Dietetic Association, 108(10), 1716-1731. http://dx.doi.org/10.1016/j. jada.2008.08.007. PMid:18953766

Sluimer, P. (2005). Principles of breadmaking: functionality of raw materials and process steps. St Paul: AACC Inc. $212 \mathrm{p}$.

Soares Júnior, M., Bassinello, P. Z., Caliari, M., Gebin, P. F. C., Junqueira, T. L., Gomes, V. A., \& Lacerda, D. B. C. L. (2009). Qualidade de pães 
com farelo de arroz torrado. Ciência e Tecnologia de Alimentos, 29(3), 636-641. http://dx.doi.org/10.1590/S0101-20612009000300028.

Sullivan, P., O’Flaherty, J., Brunton, N., Arendt, E., \& Gallagher, E. (2010). Fundamental rheological and texture properties of doughs and breads produced from milled pearled barley flour. European Food Research and Technology, 231(3), 441-453. http://dx.doi. org/10.1007/s00217-010-1297-4.
Wang, J., Rosell, C. M., \& Barber, C. B. (2002). Effect of the addition of different fibres on wheat dough performance and bread quality. Food Chemistry, 79(2), 221-226. http://dx.doi.org/10.1016/S03088146(02)00135-8.

Zobel, H. F., \& Kulp, K. (1996). The staling mechanism. In R. E. Hebeda \& H. F. Zobel (Eds.), Baked goods freshness: technology, evaluation and inhibition of staling (cap. 1, pp.1-64). New York: Marcel Dekker. 